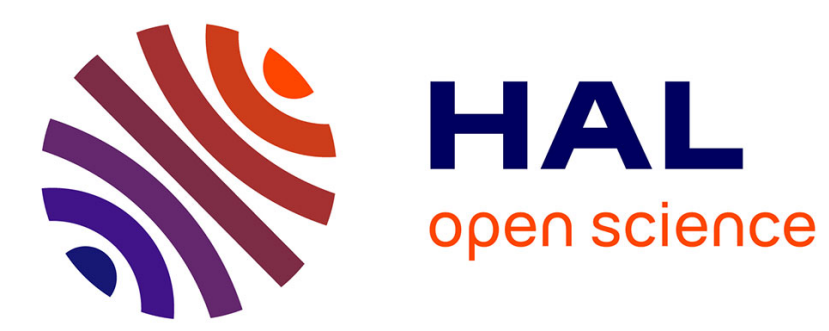

\title{
EXPERIMENTAL STUDY OF A FREE-VORTEX AERODYNAMIC WINDOW
}

\author{
W. Masuda, M. Yuasa
}

\section{To cite this version:}

W. Masuda, M. Yuasa. EXPERIMENTAL STUDY OF A FREE-VORTEX AERODYNAMIC WINDOW. Journal de Physique Colloques, 1980, 41 (C9), pp.C9-423-C9-429. 10.1051/jphyscol:1980957 . jpa-00220611

\section{HAL Id: jpa-00220611 https://hal.science/jpa-00220611}

Submitted on 1 Jan 1980

HAL is a multi-disciplinary open access archive for the deposit and dissemination of scientific research documents, whether they are published or not. The documents may come from teaching and research institutions in France or abroad, or from public or private research centers.
L'archive ouverte pluridisciplinaire HAL, est destinée au dépôt et à la diffusion de documents scientifiques de niveau recherche, publiés ou non, émanant des établissements d'enseignement et de recherche français ou étrangers, des laboratoires publics ou privés. 


\title{
EXPERIMENTAL STUDY OF A FREE-VORTEX AERODYNAMIC WINDOW
}

\author{
W. Masuda and M. Yuasa \\ Research Institute, Ishikawajima-Harima Heavy Industries, 1-15, Toyosu 3 chome, Koto-Ku, \\ Tokyo 135, Japan.
}

\begin{abstract}
A model of a supersonic free-vortex aerodynamic window has been fabricated and tested. Aerodynamic performance studies show the effectiveness of the model in sealing the simulated laser cavity from higher pressure ambient surroundings. Good starting characteristics and stability of the supersonic window jet are obtained. Static pressure measurements and photographs of the flow fields clearly show the enhanced mixing in the outer boundary of the curved jet and reduced mixing in the inner boundary due to the influence of centrifugal force. The diffuser design which compensates for the growth of the jet resulting from the mixing on each side is discussed and close agreement of the measured cavity pressure with its design value is achieved.
\end{abstract}

\section{INTRODUCTION}

In high power lasers, the extraction of a laser beam from a cavity through a solid window is difficult since the heating caused by the absorption of laser energy may distort the window. Instead of solid materials, an aerodynamic window makes use of a nonabsorbing gas jet to permit the extraction of a laser beam and support the pressure difference between the lasing gas and atmosphere. Parmentier et. a1. (1) suggested the use of a jet supply nozzle which delivers a uniform flow at its exit. In this system, high mass flow rate is required and the change in the jet momentum due to the pressure difference is accompanied with an oblique shock wave and/or a centered expansion fan which introduce the beam quality degradation. Recent advances in the aerodynamic window design have overcome these problems. An ingenious concept proposed by Guile(2)(3) utilizes a nozzle to create a free-vortex window jet. The radius of curvature of the vortex is chosen so that the constant pressure streamline on the laser side of the vortex flow matches the lasing gas pressure. The constant pressure streamline matching the atmospheric pressure is the outer streamline.

In the present investigation, a model of a supersonic free-vortex aerodynamic window has been fablicated. The cavity pressure maintained by the supersonic jet and static pressure distributions in the jet are measured to show the effectiveness of the model as an aerodynamic window. The shadow and schlieren photographs are used to observe the flow field and a design to give good performance is discussed.

\section{EXPER IMENTAL APPARATUS}

The apparatus used in the present experiment is shown in Fig.1. The working gas is stored in air cylinders of 150 $\mathrm{kg} / \mathrm{cm}^{2}$ and supplied to the nozzle plenum chamber through manually and air operated ball valves and an air operated regulating 
valve. The aerodynamic window model consists of a supersonic nozzle, an aperture and a diffuser. Several configurations of these components are available. Three supersonic nozzles, which were designed to operate at cavity pressures of $0.1,0.075$ and $0.05 \mathrm{~kg} / \mathrm{cm}^{2}$, respectively, have been fabricated. The specification of these nozzles is shown in Table 1, in which $D$ is aperture dimension, $\theta$ is jet turning angle, $M$ is Mach number, $Q$ is mass flow rate, $h$ is nozzle throat height, $h_{\text {ex }}$ is nozzle exit height and

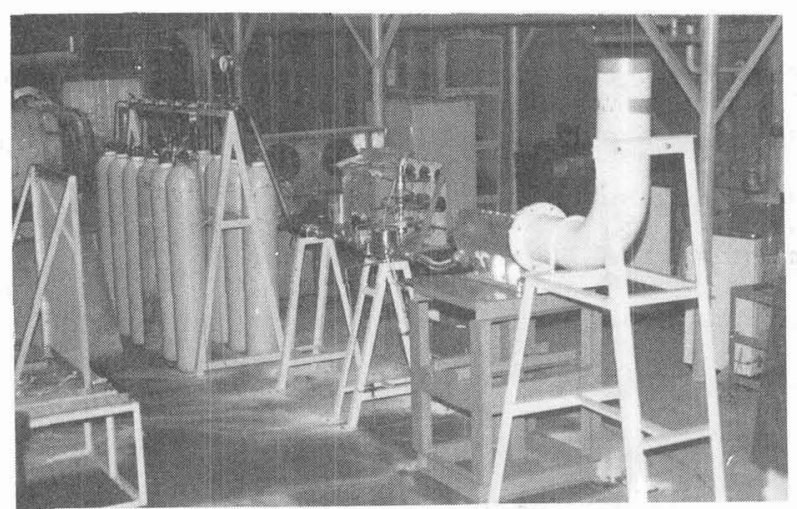

Fig.1 Experimental apparatus.

\begin{tabular}{|c|c|c|c|}
\hline Nozzle & A & B & $\mathrm{C}$ \\
\hline D $\quad \mathrm{mm}$ & 40 & 40 & 40 \\
\hline$\Theta \quad$ deg & 60 & 60 & 60 \\
\hline $\mathrm{P}_{\mathrm{O}} \quad \mathrm{kg} / \mathrm{cm}^{2}$ & 10 & 10 & 10 \\
\hline $\mathrm{P}_{1} \mathrm{~kg} / \mathrm{cm}^{2}$ & 0.1 & 0.075 & 0.05 \\
\hline $\mathrm{M}_{1}$ & 3.693 & 3.903 & 4.210 \\
\hline $\mathrm{M}_{2}$ & 2.136 & 2.136 & 2.136 \\
\hline Q $\mathrm{kg} / \mathrm{sec}$. & 0.285 & 0.295 & 0.306 \\
\hline $\mathrm{h} \quad \mathrm{mm}$ & 3.12 & 3.23 & 3.35 \\
\hline${ }^{h}$ ex & 10.04 & 10.85 & 11.91 \\
\hline
\end{tabular}

Table 1 Specification of free-vortex supply nozzles. subscripts 0,1 and 2 refer to plenum, cavity side and atmospheric side, respectively. The nozzle contour is obtained by the method of characteristics similar to that used by Guile ${ }^{(3)}$ and modified by the displacement thickness of the turbulent boundary layer. The contour of Nozzle A is shown in Fig.2. The crosssection of the aperture is a square of 4.0 $\times 4.0 \mathrm{~cm}$ or a circle of $3.8 \mathrm{~cm}$ diameter.

The aerodynamic performance of the model can be evaluated in terms of the simulated laser cavity pressure and plenum pressure of the free-vortex supply nozzle. Additional data in regard to the operation of the free-vortex aerodynamic window include the static pressure measurements in the jet and photographs of the flow

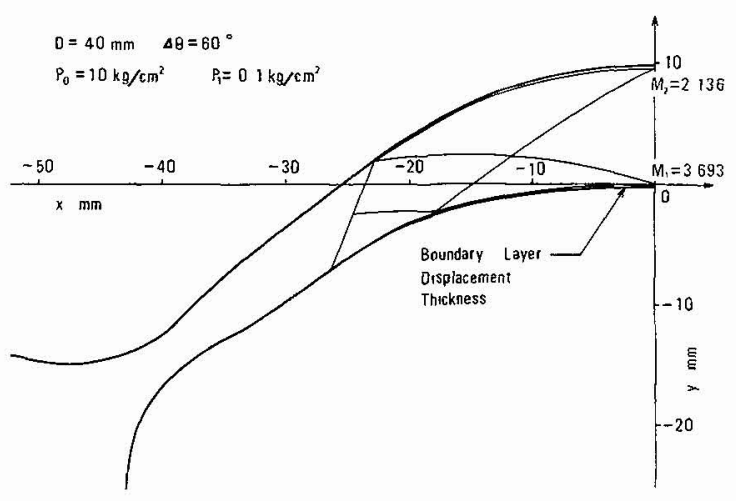

Fig.2 Contour of Nozzle A.

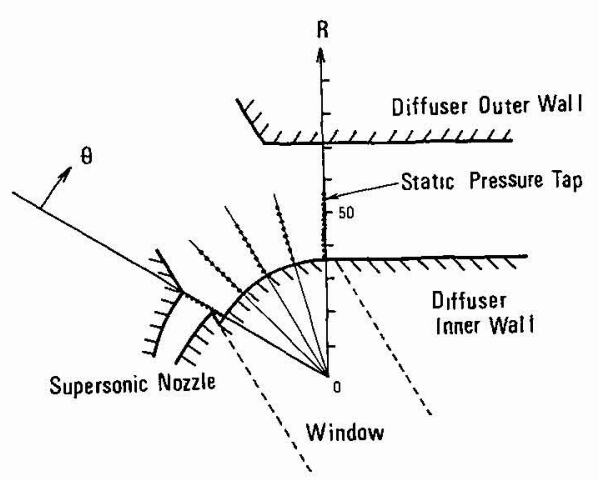

Fig. 3 Location of static pressure taps. 
field. The static pressure is measured by ninety pressure taps located on the side plates of the model. They are distributed along radial directions from the center of vortex as shown in Fig. 3 .

\section{MEASUREMENTS AND RESULTS}

Figure 4 shows the plenum and simulated cavity pressures during a window operation. The air operated regulating valve is opened and gas is supplied to the nozzle plenum chamber at $t=0.1 \mathrm{sec}$. The plenum pressure reaches its design condition of $10 \mathrm{~kg} / \mathrm{cm}^{2}$ at $t=0.6 \mathrm{sec}$. and the regulating valve is closed at $t=1.5$ sec.. One window operation is completed in a few seconds. Good starting characteristics and stability of the supersonic jet are obtained for fairly wide class of diffuser configuration. The simulated cavity pressure agrees quite well with the design value. But it depends strongly on the diffuser configuration. Figure 5 shows the dependency of the cavity pressure on the plenum pressure for the same diffuser configuration as Fig.4. The simulated cavity pressure decreases monotonously with increasing plenum pressure within the extent of this experiment.

The measured static pressure distributions in the flow field are shown in Fig.6. The pressure distribution at the nozzle exit plane agrees fairly well with the theoretical free-vortex pressure distribution as the solid line. This demonstrates that the nozzle delivers effectively a free-vortex flow field. As the mixing regions intrude on the jet downstream from the nozzle exit, the pressure along the boundaries of the jet decays. Figure 7 shows the isobars in the flow field. The vortical nature of the flow is observed and there are no evidences of strong waves within the flow field. The importance of the diffuser entrance configuration is undoubtful from this figure. The wrong diffuser design destroys the free-vortex nature of the flow not only near the diffuser entrance but also in the nozzle.

The shadowgraph obtained by using a spark light source ( $3 \mu \mathrm{sec}$.) is shown in Fig. 8. The right running characteristic

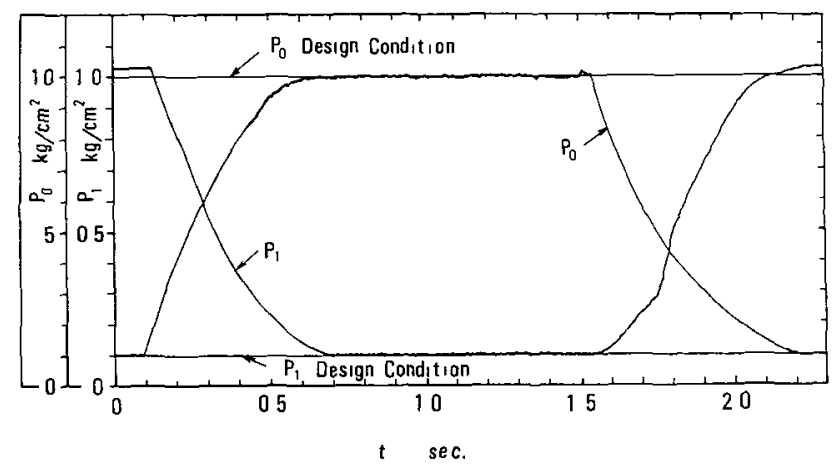

Fig.4 Plenum and cavity pressures as a function of time during window operation.

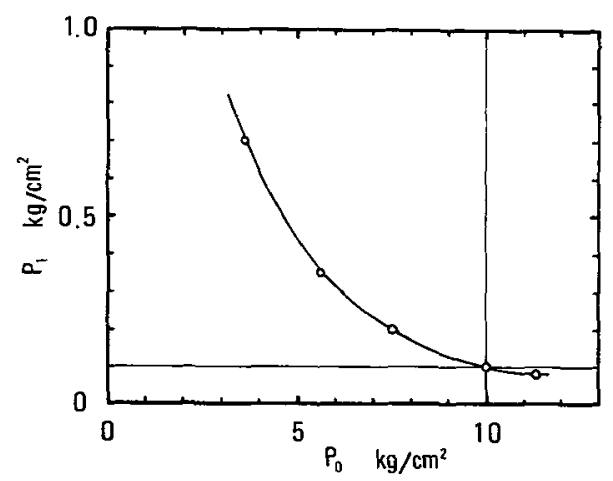

Fig.5 Dependency of cavity pressure on plenum pressure. 
lines in the nozzle seem to be stronger than the left ones. This might be due to the wrong finishing of the upper nozzle wall or the Görtler vortices. There is a slight mismatch in the pressure at each side of the nozzle exit plane. This leads to a weak shock wave on the atmospheric side and an expansion fan on the simulated cavity side at the nozzle exit. In the diffuser, the curved jet is bent to the right direction through an oblique shock

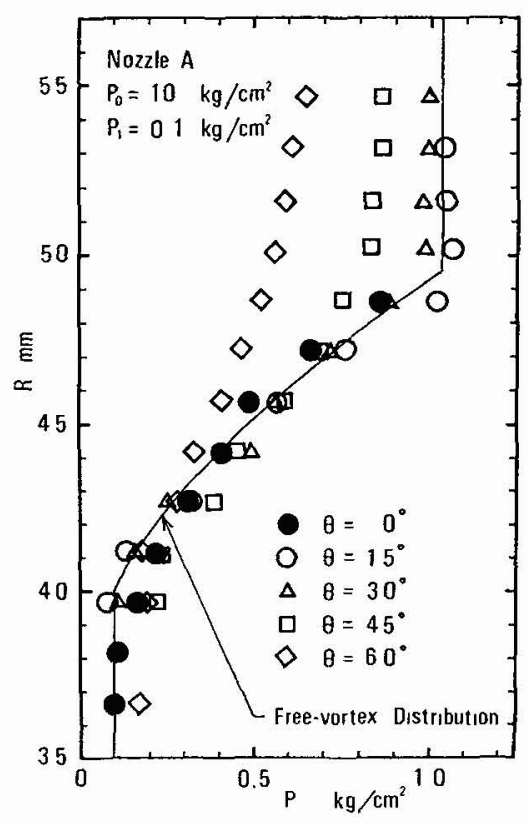

Fig.6 Static pressure distributions in the jet. wave. The shock is reflected on the upper diffuser wall and, finally, developed into a pseudo shock wave.

Figure 9 shows the off design flow field. The plenum pressure is $7.5 \mathrm{~kg} / \mathrm{cm}^{2}$ which is lower than the design value. The flow separates at the lower nozzle wall and a strong shock wave exists on the atmospheric side at the nozzle exit. Figure 10 also shows the off design flow field. In this case, the plenum pressure is $12.5 \mathrm{~kg} / \mathrm{cm}^{2}$ which is higher than the design value. The strong expansion fan is observed on the atmospheric side at the nozzle exit plane.
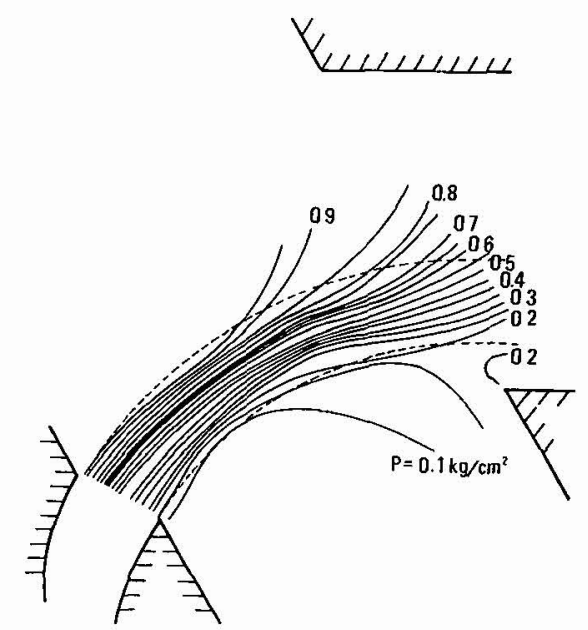

Fig. 7 Isobars in the flow field.

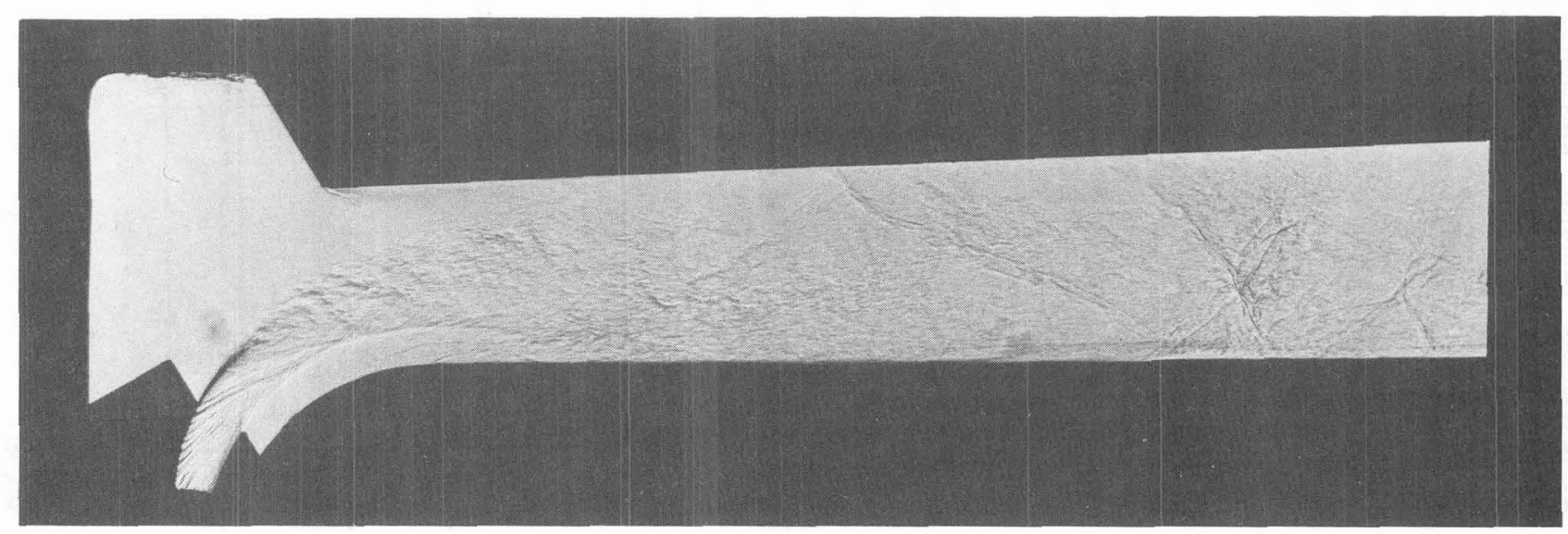

Fig. 8 Shadowgraph of the flow field in which design cavity pressure is achieved. 
Figure 8 shows the strong turbulent mixing on the atmospheric side of the jet. Eddies are observed along the outer boundary intruding on the inviscid portion of the jet as it spans the aperture. The patterns arising from the entrainment of atmosphere are clearly seen from the separation of the entrained flow at the edge of the outer diffuser wall. The inner jet boundary is in a striking contrast to the outer boundary. The measured curvature of the inner boundary shows good agreement with the design condition. The effect of curvature on the rate of entrainment by two dimensional jet was first put forward by Prandt ${ }^{(4)}$. The study of Prandt 1 shows that there should be an enhanced mixing in the outer boundary of a curved jet and a reduced mixing in the inner boundary due to the influence of centrifugal force on the parcels of fluid which transfer momentum from layer to layer. In Fig.11, we consider the transport of a small parcel of fluid from station a to station $b$ nearer the outer edge of the jet. The excess velocity of the parcel over its surroundings is expressed as follows:

$$
U_{a}-U_{b}=-l(\partial U / a Y)
$$

where $l$ is the mixing length. Then the centrifugal force imposed upon the unit mass of the parcel is larger than that upon its surroundings by

$$
\mathrm{U}_{a}^{2} / \mathrm{R}-\mathrm{U}_{\mathrm{b}}^{2} / \mathrm{R}=-2 l \mathrm{U}(\mathrm{U} / \partial \mathrm{Y}) / \mathrm{R} .
$$

Since the pressure gradients and centrifugal forces balance in the mean, the parcel is subjected to a total force of $-2 L U(\partial U / \partial Y) / R$ tending to move it further outward. Including the effect of the centrifugal force, Prandt1's expression for turbulent shear becomes

$$
\tau=\rho \tau^{2}|\partial U / \partial Y|(\partial U / \partial Y-k U / R),
$$

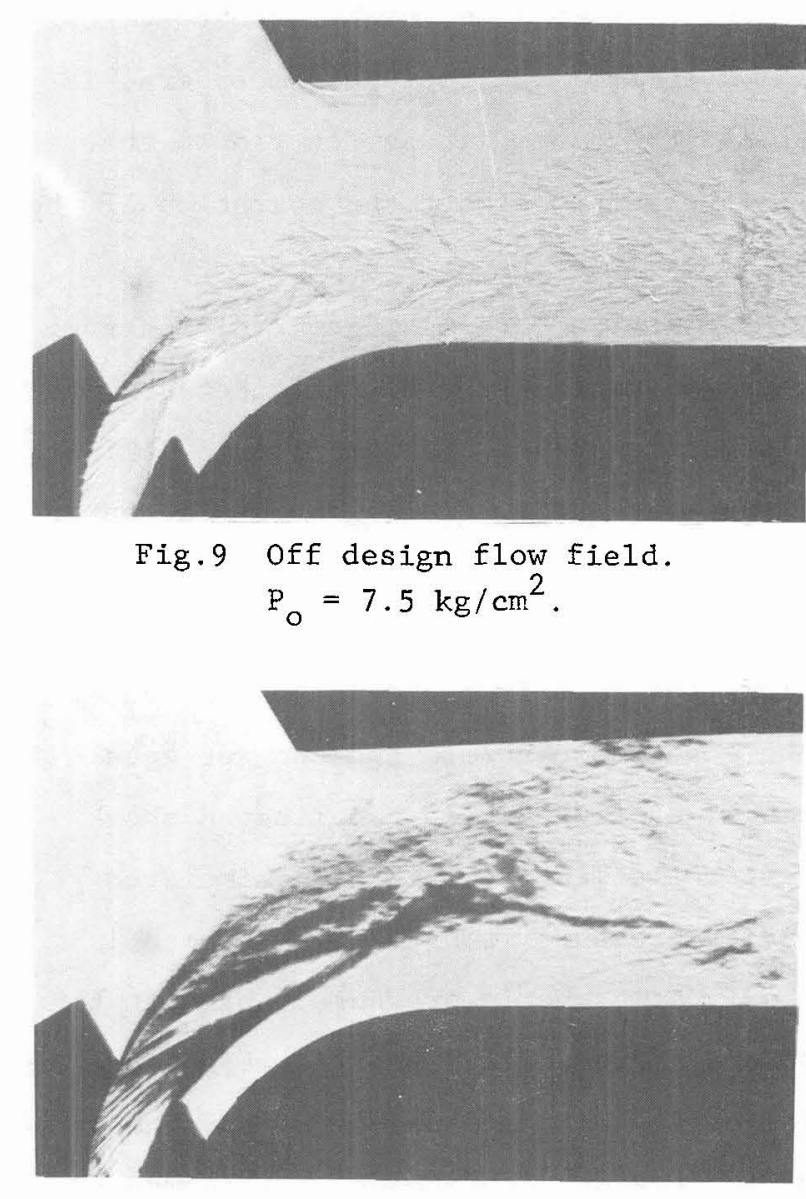

Fig.10 off design flow field.

$$
\mathrm{P}_{\mathrm{O}}=12.5 \mathrm{~kg} / \mathrm{cm}^{2} \text {. }
$$

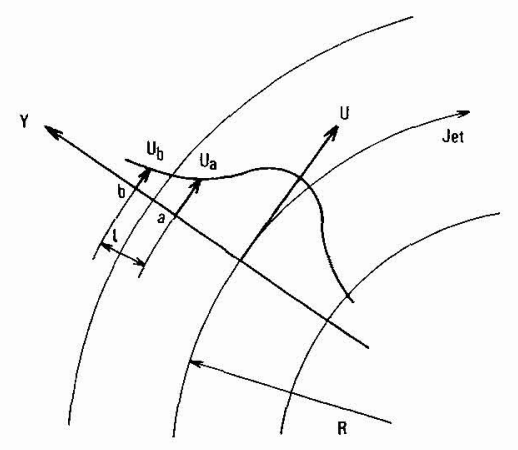

Fig.11 Effect of curvature on the turbulent mixing of a jet. 
where $k$ is an empirical constant. In the present supersonic free-vortex jet, the curvature seems to have a considerable effect on the mixing rate, since $U / R$ is very large and the turbulent shear due to the centrifugal force cannot be ignored. This mixing region, which is composed of air both from the jet and atmosphere, is so large at the diffuser entrance, that it is expected to affect the operation of the diffuser. The parameter of primary importance in determining the diffuser performance is the area ratio between the diffuser entrance and nozzle exit. Figure 12 shows the flow field without the outer diffuser wall. The supply pressure is the design value of $10 \mathrm{~kg} / \mathrm{cm}^{2}$. However, the flow separates from the inner surface of the supersonic nozzle and the jet goes nearly straight. The complicated shock waves exist in the jet. The simulated cavity pressure is $0.96 \mathrm{~kg} / \mathrm{cm}^{2}$ which is nearly atmospheric pressure. Without the outer diffuser wall, the flow ejected from the cavity by the presence of the inner mixing region seems to be small compared to the reversed flow from the diffuser.

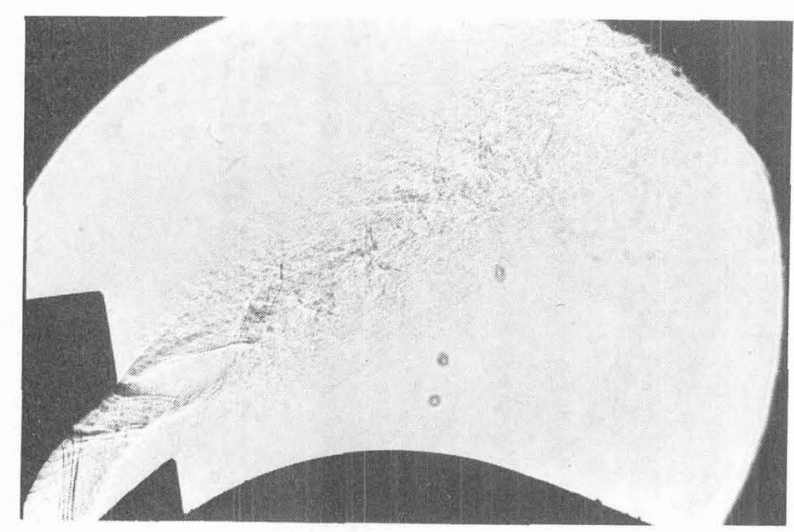

Fig.12, Flow field without outer diffuser wall.
A movable flow deflector used by Guile ${ }^{(2)}$ might be useful to guide the flow during the starting transient. Figure 13 shows the flow in which the outer diffuser wall nearly coincides with the outer turbulent mixing region. The flow is stable and no strong shock waves are observed in the aperture region. However, the measured cavity pressure is $0.18 \mathrm{~kg} / \mathrm{cm}^{2}$, which is considerably higher than the design value of $0.1 \mathrm{~kg} / \mathrm{cm}^{2}$. Testing has shown that the outer diffuser wall should be higher than that shown in Fig.13. The optimum area ratio between the diffuser entrance and nozzle exit is about 4.

There must be some leakage from the atmospheric side of the jet to the cavity as a result of the secondary flows ${ }^{(5)}$. which develop near the window side walls. The competition between the rates of this leakage and the ejection by the inner mixing region influences on the simulated cavity pressure. If the space to compensate for the growth of the jet resulting from its inner mixing is not sufficient, the air in the simulated cavity is not ejected enough to maintain

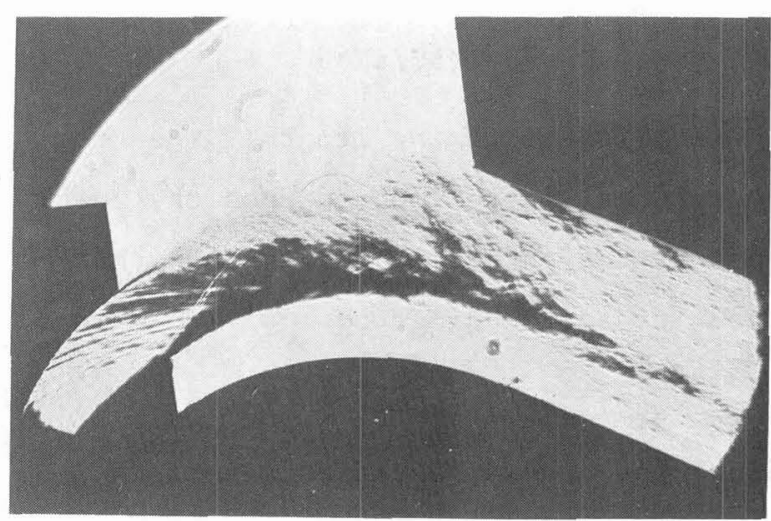

Fig. 13 Flow field with narrow diffuser inlet height. 
the desired cavity pressure. A strong shock wave appears on the cavity side at the nozzle exit plane as shown in Fig.14. The simulated cavity pressure is 0.25 $\mathrm{kg} / \mathrm{cm}^{2}$. The jet seems to be pushed upward. Therefore, it is neccessary to set the inner diffuser wall about a half of the nozzle exit height nearer to the center of the vortex from the inviscid inner boundary of the jet as shown in Fig. 8 .

\section{CONCLUSION}

In the present experiments, good starting characteristics and stability of the supersonic window jet are obtained. The static pressure measurements in the jet show that the supersonic nozzle delivers effectively a free-vortex flow field. However, the simulated cavity pressure and the decay process of the free-vortex distribution in the jet are strongly dependent on the diffuser entrance configuration. The shadow and schlieren photographs of the flow fields clearly show the enhanced mixing in the outer boundary of the curved jet and the reduced

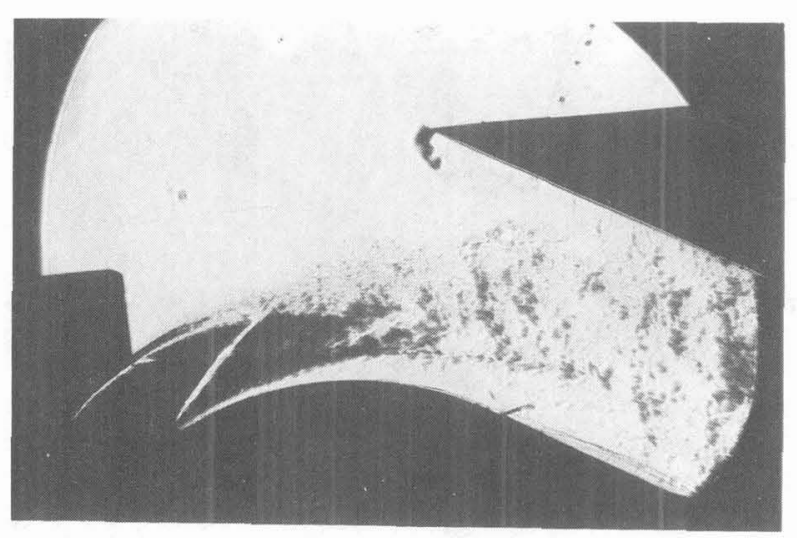

Fig.14 Flow field with insufficient space between inviscid jet boundary and inner diffuser wal1. mixing in the inner boundary due to the influence of centrifugal force. The diffuser design is discussed to compensate for the growth of the jet resulting from the mixing on each side. With appropriate diffuser design, the measured cavity pressure agrees quite well with its design value. No strong waves are observed in the aperture region. These results clearly confirm the feasibility of the free-vortex aerodynamic windows.

\section{ACKNOWLEDGMENT}

The authors wish to thank Mr.K.

Kitagawa of First Research Center of Japan Defence Agency for his kind support to this study.

\section{REFERENCES}

1. E.M.Parmentier and R.A.Greenberg, AIAA J . ,Vo1.11, No. 7, 1973, p. 943.

2. R.N.Guile, S.N.mapes, Jr.,M.N.Director and L.J.Coulter, AIAA Paper, No.74-227, 1974.

3. R.N.Guile,AIAA Paper, No.75-122,1975.

4. L.Prandt1, Vorträge aus dem Gebiete der Aerodynamik und verwandete Gebiete, Aachen 1929.Berlin: Springer, 1930.

5. H.Schlichting, Boundary-Layer Theory, New York:McGraw-Hi11, 1968,p. 213. 